\title{
FISSURAS EM PAREDES DE CONCRETO EM UM CONJUNTO RESIDENCIAL, LOCALIZADO EM SÃO JOSÉ DE RIBAMAR - MARANHÃO
}

\section{ARTIGO ORIGINAL}

LIMA, Kennedy Bruno Araújo ${ }^{1}$

BORBA, Fernando Vasconcelos ${ }^{2}$

ROCHA, Jorcelan Pereira da ${ }^{3}$

PAIXÃO, Marcos Aurélio dos Santos ${ }^{4}$

ARAÚJO, Wendel Melo Prudêncio de ${ }^{5}$

VIANA, Saymo Wendel De Jesus Peixoto ${ }^{6}$

NUNES, Larysse Lohana Leal ${ }^{7}$

LIMA, Kennedy Bruno Araújo. Et al. Fissuras em paredes de concreto em um conjunto residencial, localizado em São José de Ribamar - Maranhão. Revista Científica Multidisciplinar Núcleo do Conhecimento. Ano 05, Ed. 04, Vol. 05, pp. 148 163. Abril de 2020. ISSN: 2448-0959, Link de

${ }^{1}$ Engenheiro Civil.

2 Mestrando em Estruturas e Construção Civil. Especialista em Estruturas e Fundações.

${ }^{3}$ Pós-Graduado Em Infraestrutura De Transportes E Rodovias.

${ }^{4}$ Especialista em Estruturas e Fundações, Engenheiro Civil, Técnico Em Edificações.

${ }^{5}$ Doutorando Engenharia dos Materiais. Mestre em Engenharia dos Materiais.

${ }^{6}$ Mestrando em Engenharia Civil. Engenheiro Civil.

${ }^{7}$ Pós-Graduado Em Infraestrutura De Transportes E Rodovias. 
acesso: https://www.nucleodoconhecimento.com.br/engenharia-civil/fissuras-emparedes

\section{RESUMO}

Este trabalho trata de fissuras em parede de concreto, uma das principais patologias que ocorre em estruturas de concreto. Inicialmente foram levantados dados e informações sobre o conjunto residencial e sobre o sistema construtivo das edificações, realizadas visitas programadas ao local para inspeção visual de forma a analisar os problemas patológicos na estrutura de concreto, seguidas de registros fotográficos e aplicação de questionário com os moradores, onde buscou-se coletar informações sobre o surgimento das patologias. O estudo identificou manifestações patológicas, como fissuras, trincas e rachaduras e, em grande parte dos casos das fissuras em estruturas são mais comuns em dois pontos: nos locais onde existem componentes do sistema elétrico, e nos cantos dos vãos das portas. Portanto, a ocorrência de fissuras nas unidades do grupo amostral, foi de $100 \%$, em $70 \%$ das unidades, as fissuras já se transformaram para trincas e em 10\% dos casos, já é visível a incidência de rachaduras. Deste modo, tais patologias demonstram a existência de riscos a segurança da estrutura de concreto e a integridade dos moradores. Sendo assim, com problemas de patologias em grande evolução na estrutura, que podem consequentemente aumentar agressivamente no decorrer do tempo, seria adequado que fosse tomada medidas de proteção da estrutura, com a implantação manutenção periódica, para evitar o agravo das patologias identificadas.

Palavras-chave: Manifestações patológicas, fissuras, concreto.

\section{INTRODUÇÃO}

O déficit habitacional no Brasil possui destaque no contexto social, fazendo com que o governo tenha a iniciativa de investir no setor da construção civil. Diante dessa problemática, surgem programas de habitação, com a finalidade de reduzir tal déficit, proporcionando, viabilizando e oportunizando a aquisição de um domicílio decente para o público mais pobre, que representa uma grande parte que possui tal déficit. 
O Programa Minha Casa, Minha Vida (MCMV) é um Programa de Habitação, fundado em 2009, que surgiu com o objetivo de tornar a moradia mais acessível ao cidadão brasileiro e reduzir o déficit habitacional, que informa a necessidade de construção de moradias populares para a solução de problemas sociais e específicos de habitação e a inadequação dos domicílios, que reflete problemas na qualidade de vida dos moradores, em que muitas das habitações existentes, não atendem dignamente os moradores.

No ano de 2009, houve uma grande demanda por habitações populares. Essa demanda forçou o mercado da construção civil a investir em sistemas inovadores, que utilizassem métodos construtivos racionalizados, que representa um menor consumo de mão de obra e otimização de tempo de execução, devido a utilização de produtos e processos industrializados.

Sendo assim, foi retomado um sistema construtivo, que já era utilizado no Brasil desde 1970, porém a tecnologia não foi consolidada no mercado brasileiro por não existir demanda suficiente para tornar sua utilização viável. Entretanto, por constituir uma solução para a geração em alta escala, quando se trata de redução do déficit habitacional, o sistema construtivo paredes de concreto moldadas in loco, foi recuperado pelas grandes construtoras por apresentar uma grande eficácia na produção em relação aos sistemas convencionais, além de reduzir custos e garantir qualidade na execução de unidades habitacionais.

Consequentemente, as construtoras enfrentaram grandes dificuldades quando se trata de funcionários de elevada qualificação, devido a escassez da mão de obra qualificada. Sendo assim, algumas causas que podem garantir qualidade a uma edificação, como técnicas construtivas, materiais empregados, mão de obra qualificada, entre outros.

Tendo em vista que os problemas de patologias influenciem diretamente na durabilidade, vida útil e desempenho das estruturas de concreto, busca-se identificar e mensurar a tipologia das manifestações patológicas nas estruturas de concreto, desenvolvendo gráficos e tabelas que evidenciem o seu ordenamento percentual e a 
incidência dessa patologia no grupo amostral do conjunto residencial. Contudo, o grupo amostral das unidades habitacionais do conjunto residencial em estudo, composto por 30 unidades, representa $0,74 \%$ do total de 4.051 unidades, o que consiste em uma limitação da pesquisa realizada, sendo analisado um grupo amostral para o levantamento de dados. Devido a fatores como tempo, não foi possível verificar um maior número de unidades, não sendo possível abranger a totalidade de estruturas que apresentam incidências patológicas.

\section{REVISÃO BIBLIOGRÁFICA}

$\mathrm{Na}$ execução de serviços com concreto simples ou armado deve haver diversos critérios a serem adotados para que os elementos apresentem uma boa qualidade, assim, as estruturas de concreto devem apresentar características essenciais em sua execução, tais como: capacidade, resistência e durabilidade (NBR 6118, 2014). Com isso, destaca-se que o concreto armado é formado da aderente entre o concreto e o aço, mais bem especificado na ABNT - NBR 6118 (2014).

O concreto armado, assim denominado por trabalhar com a junção entre o concreto simples e vergalhões de aço, apresenta a seguintes vantagens: durabilidade, resistência à compressão, trabalhabilidade, resistência a choques e vibrações. Entretanto, as estruturas de concreto apresentam algumas desvantagens, estas são: elementos com maiores dimensões em comparação com as estruturas de aço, peso/custo superior a outros materiais, necessidade do uso de fôrmas e escoras (CARVALHO; FIGUEIREDO, 2011).

\subsection{DURABILIDADE E VIDA ÚTIL}

De acordo com a NBR 6118 (2014), durabilidade está ligada com as propriedades do concreto armado, especificadamente, a resistência em aspectos ambientais e técnicos, no que se refere à vida útil da estrutura. Ou seja, no final da durabilidade de um material, se conclui que o período de sua vida útil já terminou, com isso, o concreto pode deteriorar e se tornar propício ao colapso estrutural. No gráfico 1 é observado a relação desempenho x tempo, demostrando a importância da durabilidade. 
Gráfico 1 - Fases do desempenho de uma estrutura durante sua vida útil.

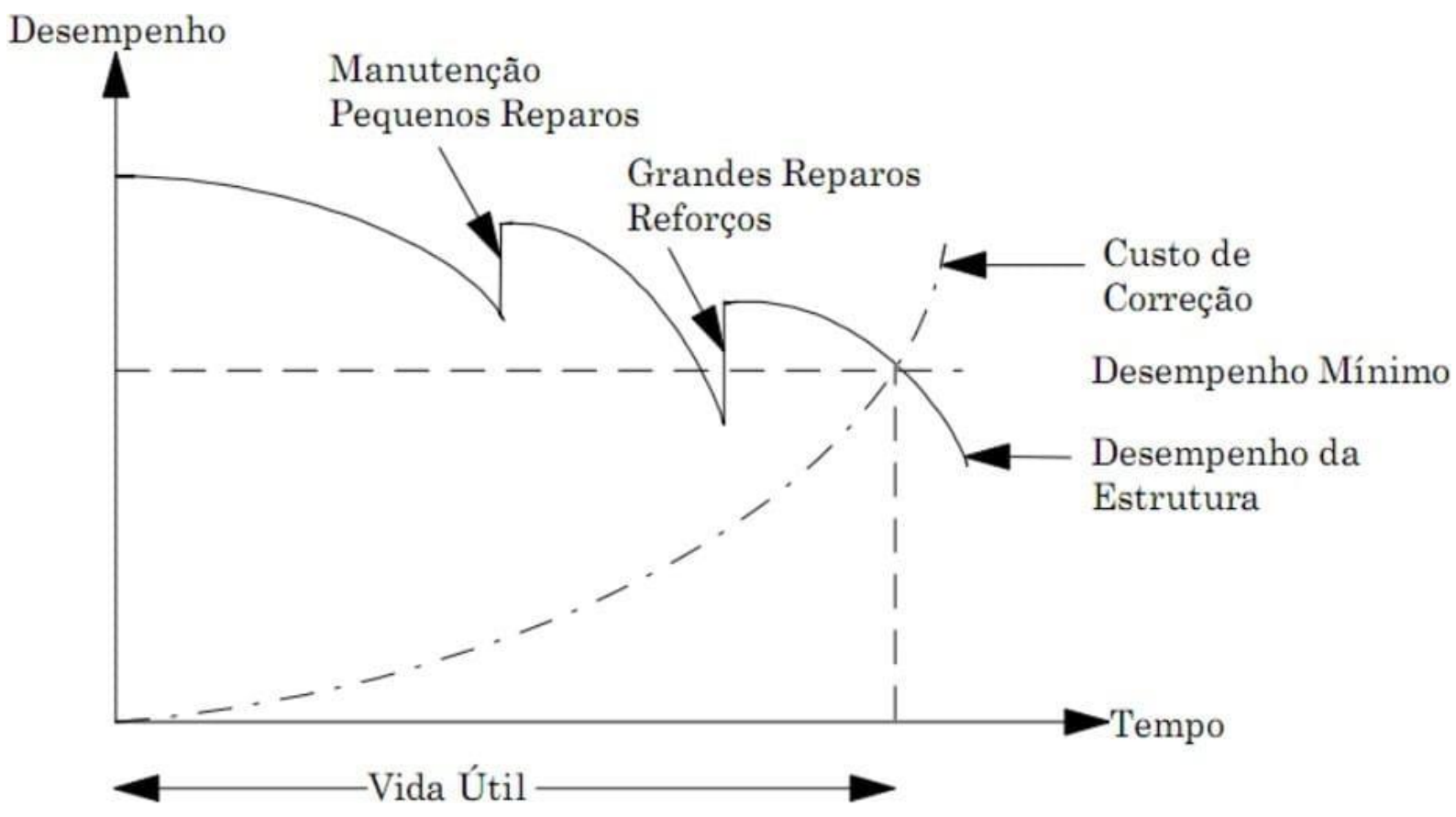

Fonte: ANDRADE (1997)

\subsection{PATOLOGIAS DO CONCRETO ARMADO}

Lottermann (2013) afirma que as manifestações patológicas são os principais motivos que aceleram o final da vida útil do concreto armado, assim, na ocorrência de defeitos deve ser aplicada uma manutenção periódica nos elementos afetados, o que ocasionará menores custos de reparação no decorrer do tempo. Dessa maneira, na maioria dos casos, os defeitos só se manifestam depois de muito tempo em que a edificação foi construída, entretanto, erros de projeto e execução podem acelerar o surgimento dessas patologias para os primeiros anos de uso, assim, todas as fases são importantes no processo da construção (ALMEIDA, 2008).

O concreto armado (cimento, areia, brita, água e aço) não é um material inerte, assim, pode sofrer modificações com o decorrer do tempo através de diversos agentes externos (PIANCASTELLI, 1997). Dessa maneira, o contato entre o concreto e esses agentes podem ocasionar diversos tipos de defeitos nas estruturas, afetando não apenas a condição estrutural do edifício, mas também a estética e seu aspecto funcional (ANDRADE; SILVA, 2005). 
Logo, para o tratamento da patologia no concreto, é necessária uma inspeção cuidadosa do local, o diagnóstico correto da patologia e a elaboração de um plano de manutenção corretiva.

\subsection{MANIFESTAÇÕES PATOLÓGICAS}

\subsubsection{FISSURAS, TRINCAS E RACHADURAS}

As fissuras, trincas e rachaduras são defeitos que se manifestam em alvenarias, vigas, pilares, lajes, pisos, entre outros, na maioria das vezes, gerados por esforços elevados sobre os materiais. Entretanto, destaca-se que as fissuras são os defeitos que mais são encontrados nas construções (OLIVEIRA, 2012).

Como demonstrado no Quadro 1, a diferença entre fissuras, trincas, rachaduras, fenda e brecha está em sua dimensão (abertura). Com isso, para manutenção dos locais afetados por esses defeitos é preciso à criação de um plano de manutenção que analise a edificação de forma aprofundada (LOTTERMANN, 2013).

Quadro 1 - Classificação das anomalias de acordo com as aberturas

\begin{tabular}{|l|l|}
\hline Anomalias & Aberturas $(\mathrm{mm})$ \\
\hline Fissura & Até 0,5 \\
\hline Trinca & De 0,5 a 1,5 \\
\hline Rachadura & De 1,5 a 5,0 \\
\hline Fenda & De 5,0 a 10,0 \\
\hline Brecha & Acima de 10,0 \\
\hline
\end{tabular}

Fonte: OLIVEIRA (2012)

\subsubsection{CORROSÃO DAS ARMADURAS}

É um defeito que aumenta a velocidade de degradação das estruturas de concreto armado, através de um fenômeno eletroquímico, especificadamente, por causa da existência de agentes químicos internos ou externos ao concreto. Assim, por se 
encontrar submerso em meio alcalino (básico no concreto), o aço agirá de forma passiva, passando por transformações onde houver o contato com cloretos, sulfatos e sulfetos (LOTTERMANN, 2013).

Lottermann (2013) acrescenta que na ocorrência da corrosão de armaduras, os vergalhões de aço se expandem até oito vezes no local atingido, ocasionando fissuras por caso dos esforços gerados de forma interna ao concreto, tornando a armadura mais exposta à atuação dos agentes nocivos, o que ocasiona outra patologia, denominada de desplacamento. Para a NBR 6118 (2014) o nível de agressividade gerado pela corrosão das armaduras está relacionado diretamente com o ambiente, dessa maneira, os níveis aceitáveis são: $0,1 \mathrm{~mm}$ para elementos não protegidos em ambientes agressivos; $0,2 \mathrm{~mm}$ para elementos não protegidos em ambientes não agressivos; $0,3 \mathrm{~mm}$ para elementos protegidos.

\subsubsection{DESAGREGAÇÃO}

Para Souza e Ripper (1998), na ocorrência de fissuras nos elementos de concreto armado, surge também, no decorrer do tempo, a desagregação que é a separação física de placas de concreto. Ou seja, na ocorrência da segregação a estrutura não trabalhará mais de forma monolítica, pois existe a perda da ligação que ocorre entre os agregados.

Assim, entre outras causas, a desagregação é ocasionada pelas fissuras nos elementos estruturais; ocorrência de locomoção das fôrmas; corrosão e calcinação do concreto e, até mesmo, ataques biológicos. Sendo que, após a ocorrência dessa patologia, a estrutura diminuirá grandemente sua resistência a tensões atuantes (SOUZA; RIPPER, 1998).

\subsubsection{SEGREGAÇÃO}

Os elementos que formam o concreto em estado fresco estão propícios à separação no período de transporte, lançamento e adensamento. Esta separação é denominada de segregação. Especificadamente, a segregação pode ocorrer por causa da má 
vibração ou pelo lançamento incorreto do concreto, ocasionando a separação dos agregados graúdos em relação à argamassa, o que gera um elevado índice de vazios e porosidade. Sendo que os espaços gerados pela segregação possibilitam a infiltração de água e outros agentes nocivos à estrutura (ANDRADE; SILVA, 2005).

\subsection{PAREDES DE CONCRETO MOLDADAS NO LOCAL}

Para Corsini (2010) o sistema é composto de forma simples por um conjunto de fôrmas, armaduras centralizadas (telas eletrosoldadas), e pelo elemento principal que é o concreto, que de acordo com a NBR 16055 (2012), deve apresentar uma resistência característica à compressão $\leq 40 \mathrm{Mpa}$.

Para Ponzoni (2013), a escolha na execução do método de paredes monolíticas de concreto moldadas no local, é visto de forma ruim, pois apresenta um custo inicial alto, entretanto, existem diversas vantagens em sua escolha. Porquanto, é uma técnica de produção racionalizada de boa produtividade, qualidade e economia em geral, em que a vedação e a estrutura são compostas por um só artifício (MISURELI; MASSUDA, 2009).

A NBR 16055 (2012) não fixa limites para as diversas edificações, no entanto, chama de edifícios simplificados os quais apresentam as seguintes características:

- Até 5 pavimentos;

- Pé-direito máximo de $3 \mathrm{~m}$;

- Dimensões em planta de no mínimo 8 m;

- No máximo 4 m de vão livre (lajes);

- Lajes não podem ser pré-moldadas, com sobrecarga máxima de $300 \mathrm{kgf} / \mathrm{m}^{2}$.

Misurelli e Massuda (2009) cita, entre outros, que os melhores concretos utilizados nessa técnica são: concreto celular, concreto com alto teor de ar incorporado, concreto com agregados leves. E na concretagem desse sistema estrutural, entende-se que lajes e paredes formam um elemento monolítico. Sendo que as paredes, segundo a NBR 16055 (2012), podem estar expostas à carga axial, com ou sem flexão. 


\section{RESULTADOS E DISCUSSÕES}

O Residencial Nova Terra é considerado um dos maiores conjuntos habitacionais do Maranhão, construído com recursos do MCMV, as obras foram concluídas em 2012 e entregues as famílias a partir de 2013.

O empreendimento conta com 4.051 unidades habitacionais, do tipo casas térreas em que 3.865 unidades são geminadas e 186 são isoladas. O conjunto residencial ocupa uma área total de 738.779,80 m², e está localizado na parte central do município de São José de Ribamar - Maranhão, no bairro da Quinta, a 30 quilômetros de São Luís, capital do Estado do Maranhão.

Logo, trata-se de um empreendimento de grande porte, implantado em área onde o uso habitual era de sítios de recreio, portanto em região de ocupação rarefeita.

O empreendimento possui também 63.066,80 $\mathrm{m}^{2}$ destinados a áreas verdes e 19.788 $\mathrm{m}^{2}$ destinadas a uso institucional.

De acordo com os gráficos a seguir, são determinadas o total de unidades habitacionais do conjunto residencial, assim como a quantidade de unidades geminadas e isoladas (Gráfico 2) e o percentual relativo ao padrão construtivo (Gráfico $3)$.

Gráfico 2 - Da totalidade de edificações no Residencial Nova Terra

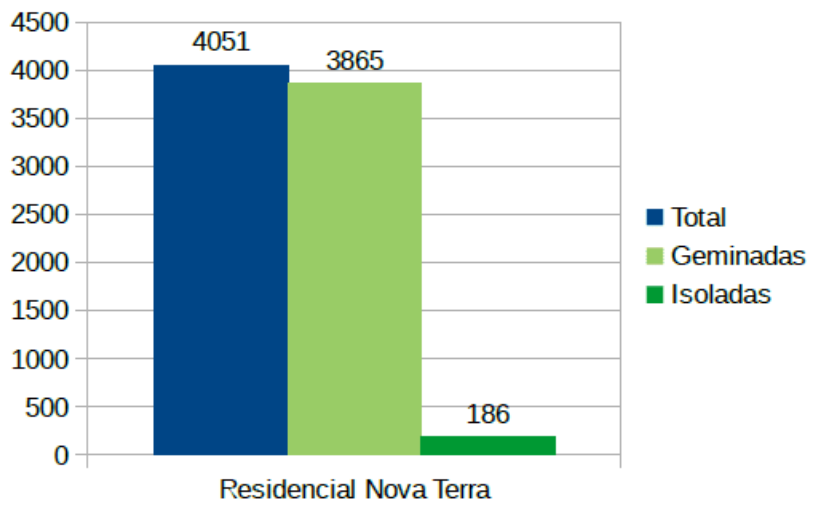

Fonte: Autores (2018). 
Gráfico 3 - Porcentagem relativa das edificações do Residencial Nova Terra

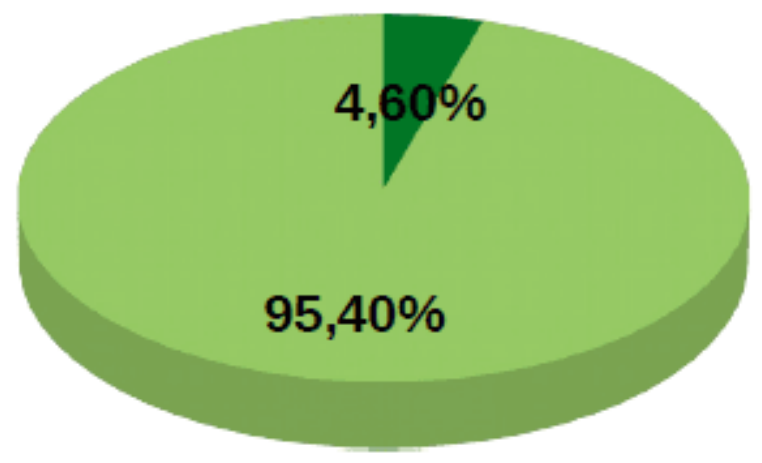

\section{Geminadas Isoladas}

Fonte: Autores (2018).

As edificações unifamiliares de interesse social, conta ainda com fundação superficial tipo radier de concreto armado com Fck de $18 \mathrm{Mpa}$, Tela Q 61 e Aço CA 60, em que foi utilizado lona plástica para a impermeabilização do radier, e conta com um sistema construtivo racionalizado das estruturas das paredes de concreto moldado in loco, com Fck de $25 \mathrm{Mpa}$ e a armação das paredes conta com telas soldadas Q 92 e Aço CA 60.

Sendo assim, foi delimitado um grupo amostral para realizar a inspeção visual das patologias nas estruturas de concreto, que conta com 30 unidades residenciais, o que representa $0,74 \%$ do total de 4.051 unidades habitacionais do conjunto residencial.

As obras que se iniciaram em 2011, realizaram-se em 10 etapas, por quatro construtoras, com dois padrões construtivos: casas geminadas e isoladas, com área de $36,05 m^{2}$ ou $36,39 m^{2}$, de acordo com o projeto arquitetônico, apresentado a seguir. 
Figura 1 - Projeto arquitetônico das unidades habitacionais do conjunto residencial

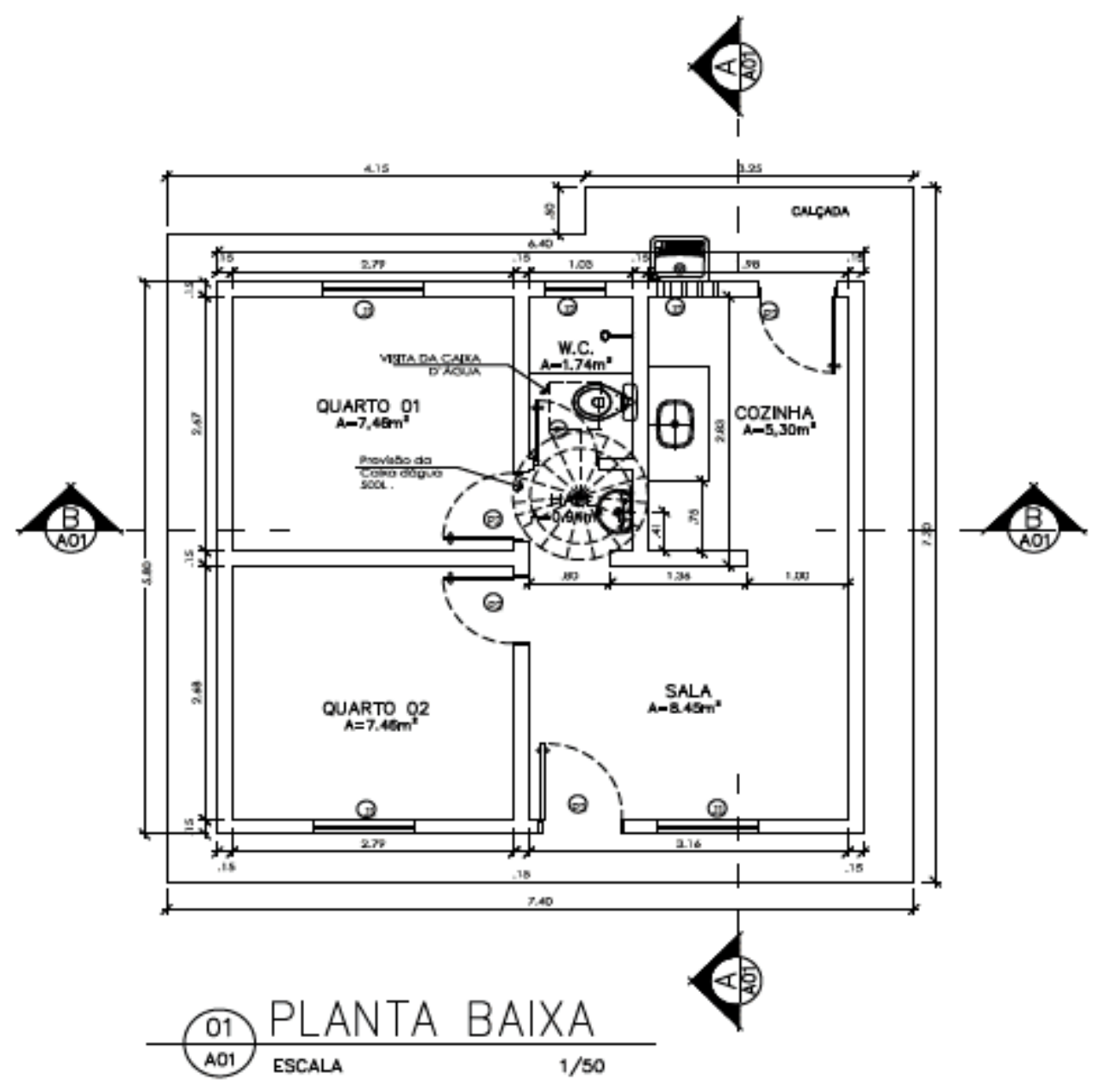

Fonte: Autores (2018).

Inicialmente, foram levantados dados e coletadas informações, através de documentações, como projeto arquitetônico e complementares, memorial descritivo, especificações técnicas, manual de uso, operação e manutenção do imóvel, entre outros, concluindo a primeira etapa de análise de dados. Após análise de dados, visitaram-se as unidades do conjunto residencial para a conferência destes dados, para dar início a sistematização empregada.

Com as manifestações patológicas que as estruturas de concreto apresentavam, foram realizadas visitas programadas ao local para inspeção visual, para medições 
das fissuras com uso do fissurômetro simples com o objetivo de se estabelecer as condições da estrutura, seguidas de registros fotográficos.

Sendo assim, ainda foram realizados questionários com os moradores, onde se pretende levantar informações sobre o surgimento das manifestações patológicas. Segundo os moradores, $90 \%$ afirmaram que as unidades habitacionais já apresentavam manifestações patológicas, quando entregues pela construtora em 2013, e 10\% afirmaram que as unidades habitacionais não apresentavam patologias, quando foi realizado pela construtora em 2013.

Entretanto, $100 \%$ afirmaram que no ano de 2018, as casas apresentam manifestações patológicas, ou seja, todas as unidades habitacionais do grupo amostral que foram analisadas, apresentam problemas de patologia, que variam de fissuras de 0,05 mm à rachaduras de $2,5 \mathrm{~mm}$. De acordo com o gráfico 3 a seguir, são analisadas as unidades habitacionais do grupo amostral, assim como a divisão do padrão construtivo. Deste modo, das 30 unidades do grupo amostral, 27 são geminadas e 3 são isoladas.

Gráfico 4 - Da totalidade de edificações do grupo amostral

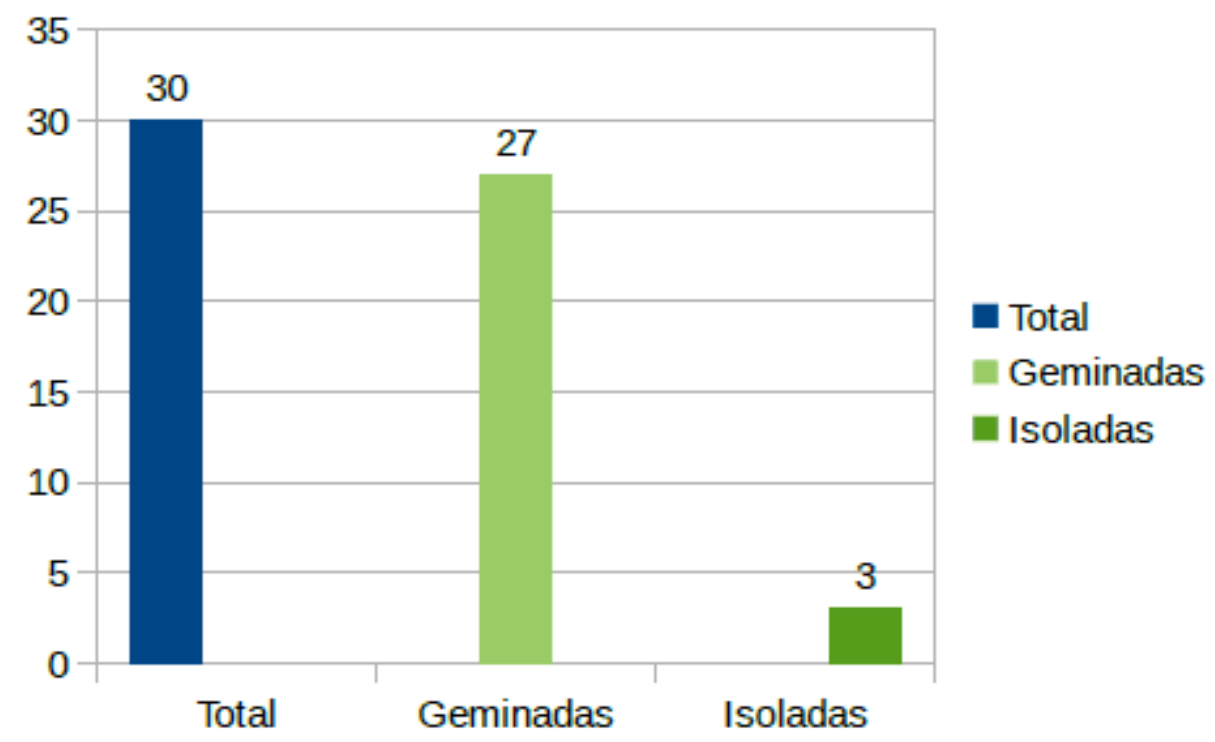

Fonte: Autores (2018). 
As patologias foram especificadas da seguinte forma: Foram investigadas e caracterizadas as manifestações patológicas em cada uma das unidades habitacionais, categorizando as principais patologias detectadas em cada edificação, como fissuras, trincas e rachaduras e calculando, a percentagem de patologias em relação ao grupo amostral.

Portanto, pode-se dizer que as 30 unidades do grupo amostral retratam fissuras que variam de $0,05 \mathrm{~mm}$ a $0,5 \mathrm{~mm}$. O local onde ocorre a incidência das fissuras, são nos cantos de portas e janelas, onde há a existência de uma armadura de reforço que visa resistir a concentração de tensões nas aberturas e em pontos onde existem componentes do sistema elétrico, onde a resistência à tração da estrutura é reduzida, essas fissuras se caracterizam de diversas formas, sendo inclinadas, verticais e horizontais, sempre partindo dos cantos das aberturas.

Veja a tabela 1 abaixo, em que foram identificadas as incidências patológicas em cada uma das unidades habitacionais do grupo amostral.

Tabela 1 - Incidência patológica no grupo amostral

\begin{tabular}{|c|c|c|c|c|c|c|c|}
\hline \multirow[b]{2}{*}{ Locais } & \multirow[b]{2}{*}{ Fissuras } & \multirow[b]{2}{*}{ Trincas } & \multirow[b]{2}{*}{ Rachaduras } & \multirow{2}{*}{\begin{tabular}{|r|} 
Locais \\
Casa 18 \\
\end{tabular}} & \multirow{2}{*}{\begin{tabular}{|c|} 
Fissuras \\
$\mathrm{x}$ \\
\end{tabular}} & \multirow{2}{*}{$\begin{array}{c}\text { Trincas } \\
\mathrm{x} \\
\end{array}$} & \multirow{2}{*}{\begin{tabular}{|c|} 
Rachaduras \\
- \\
\end{tabular}} \\
\hline & & & & & & & \\
\hline Casa 01 & $\mathrm{x}$ & $\mathrm{x}$ & - & Casa 19 & $\mathrm{X}$ & $\mathrm{x}$ & - \\
\hline Casa 02 & $\mathrm{x}$ & $\mathrm{x}$ & $\mathrm{x}$ & \multirow{2}{*}{\begin{tabular}{|l|} 
Casa 20 \\
\end{tabular}} & \multirow{2}{*}{$\mathrm{x}$} & \multirow{2}{*}{-} & \multirow{2}{*}{-} \\
\hline Casa 03 & $\mathrm{x}$ & - & - & & & & \\
\hline Casa 04 & $\mathrm{x}$ & - & - & Casa 21 & $\mathrm{X}$ & - & - \\
\hline \begin{tabular}{|l|} 
Casa 05 \\
\end{tabular} & $\mathrm{x}$ & $\mathrm{x}$ & - & Casa 22 & $\mathrm{x}$ & $\mathrm{x}$ & - \\
\hline Casa 06 & $\mathrm{x}$ & $\mathrm{x}$ & - & Casa 23 & $\mathrm{x}$ & $\mathrm{x}$ & - \\
\hline \begin{tabular}{|l|} 
Casa 07 \\
\end{tabular} & $\mathrm{x}$ & $\mathrm{x}$ & - & Casa 24 & $\mathrm{X}$ & $\mathrm{X}$ & - \\
\hline \begin{tabular}{|l|} 
Casa 08 \\
\end{tabular} & $\mathrm{x}$ & $\mathrm{x}$ & - & Casa 25 & $\mathrm{X}$ & $\mathrm{X}$ & - \\
\hline \begin{tabular}{|l|l|} 
Casa 09 \\
\end{tabular} & $\mathrm{x}$ & - & - & \multirow{2}{*}{\begin{tabular}{|l|} 
Casa 26 \\
\end{tabular}} & \multirow{2}{*}{$\mathrm{x}$} & \multirow{2}{*}{$\mathrm{X}$} & \multirow{2}{*}{-} \\
\hline \begin{tabular}{|l|l|} 
Casa 10 \\
\end{tabular} & $\mathrm{x}$ & $\mathrm{x}$ & - & & & & \\
\hline Casa 11 & $\mathrm{x}$ & $\mathrm{x}$ & - & Casa 27 & $X$ & - & - \\
\hline Casa 12 & $\mathrm{x}$ & $x$ & $\mathrm{x}$ & Casa 28 & $\mathrm{X}$ & - & - \\
\hline Casa 13 & $\mathrm{x}$ & $\mathrm{x}$ & - & Casa 29 & $\mathrm{x}$ & - & - \\
\hline \begin{tabular}{|l|} 
Casa 14 \\
\end{tabular} & $\mathrm{x}$ & $\mathrm{x}$ & - & Casa 30 & $\mathrm{X}$ & - & - \\
\hline \begin{tabular}{|l|} 
Casa 15 \\
\end{tabular} & $\mathrm{x}$ & $\mathrm{x}$ & - & \begin{tabular}{|l|} 
Total \\
\end{tabular} & 30 & 21 & 3 \\
\hline \begin{tabular}{|l|} 
Casa 16 \\
\end{tabular} & $\frac{\mathrm{x}}{\mathrm{x}}$ & $\mathrm{x}$ & - & $\%$ & $100 \%$ & $70 \%$ & $10 \%$ \\
\hline Casa 17 & $\mathrm{X}$ & $\mathrm{X}$ & $\mathrm{X}$ & & & & \\
\hline
\end{tabular}

Fonte: Autores (2018). 
É apresentado a seguir algumas imagens das fissuras nas paredes de concreto, em que esta manifestação patológica ocorre nos cantos dos vãos de portas e janelas e tem características diversas, sendo a maioria inclinadas, verticais e horizontais, sempre partindo da extremidade das aberturas.

Figura 2, 3 - Fissuras
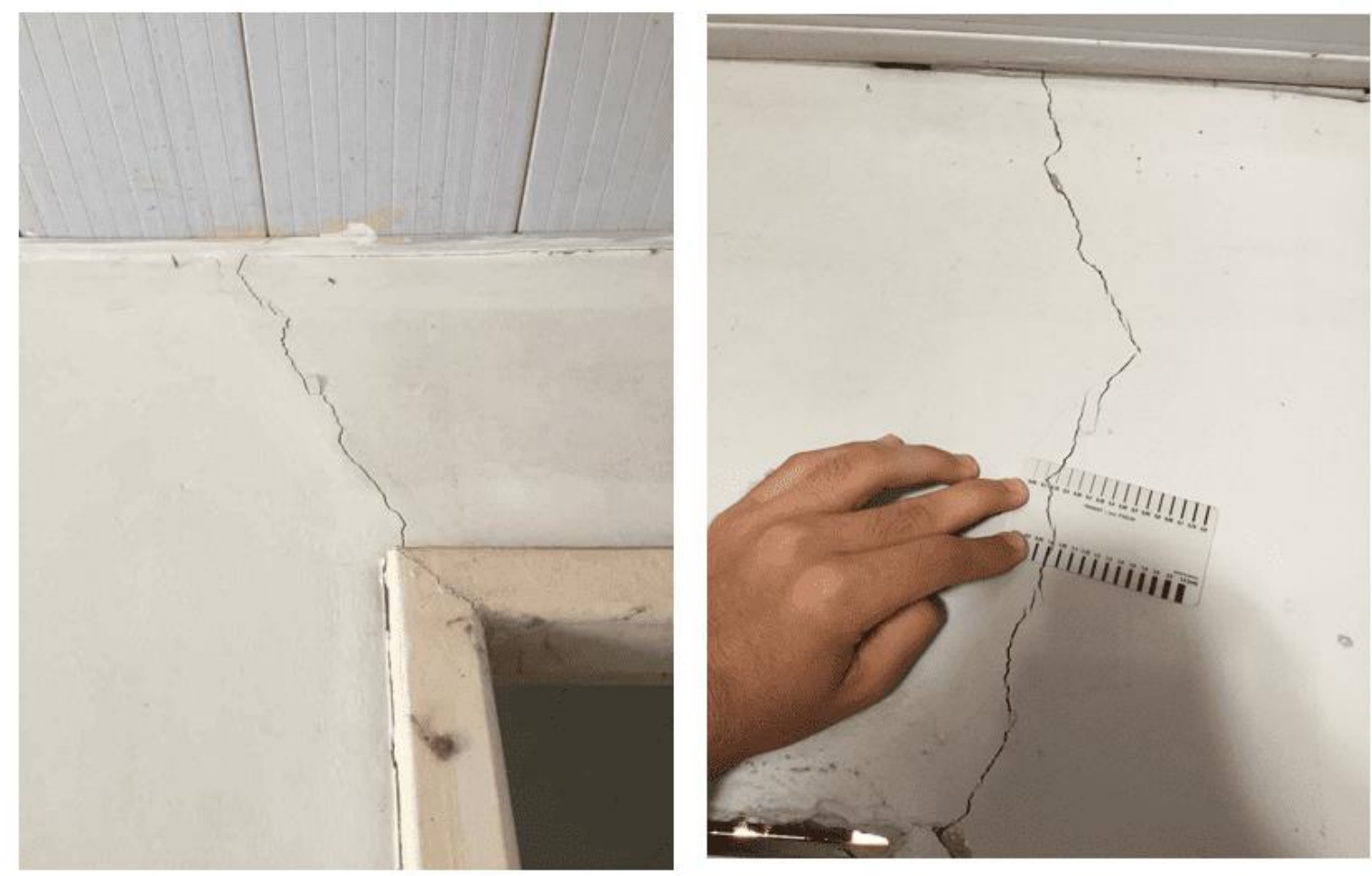

Fonte: Autores (2018).

Em 21 unidades examinadas, há ocorrência de trincas que variam de $0,5 \mathrm{~mm}$ a 1,5 $\mathrm{mm}$ de espessura das aberturas, o local onde ocorre as trincas, são nas ligações parede-parede e nas paredes mais longas, em que são utilizadas juntas de indução de fissuras e juntas de controle verticais e horizontais.

Já rachaduras, foram identificadas em 3 unidades do grupo amostral, em que as espessuras da abertura variam de $1,5 \mathrm{~mm}$ a $2,5 \mathrm{~mm}$, os locais onde foram encontradas as rachaduras foram nas paredes com máximas aberturas, nas paredes mais longas, na ligação parede-parede e nas paredes de áreas próximas onde está localizado a caixa d'água, segundo projeto arquitetônico, podendo sofrer sobrecarga, 
de acordo com as imagens a seguir, que caracterizam a incidência de trincas e rachaduras nas paredes de concreto.

Figura 4, 5, 6, 7 - Trincas e rachaduras
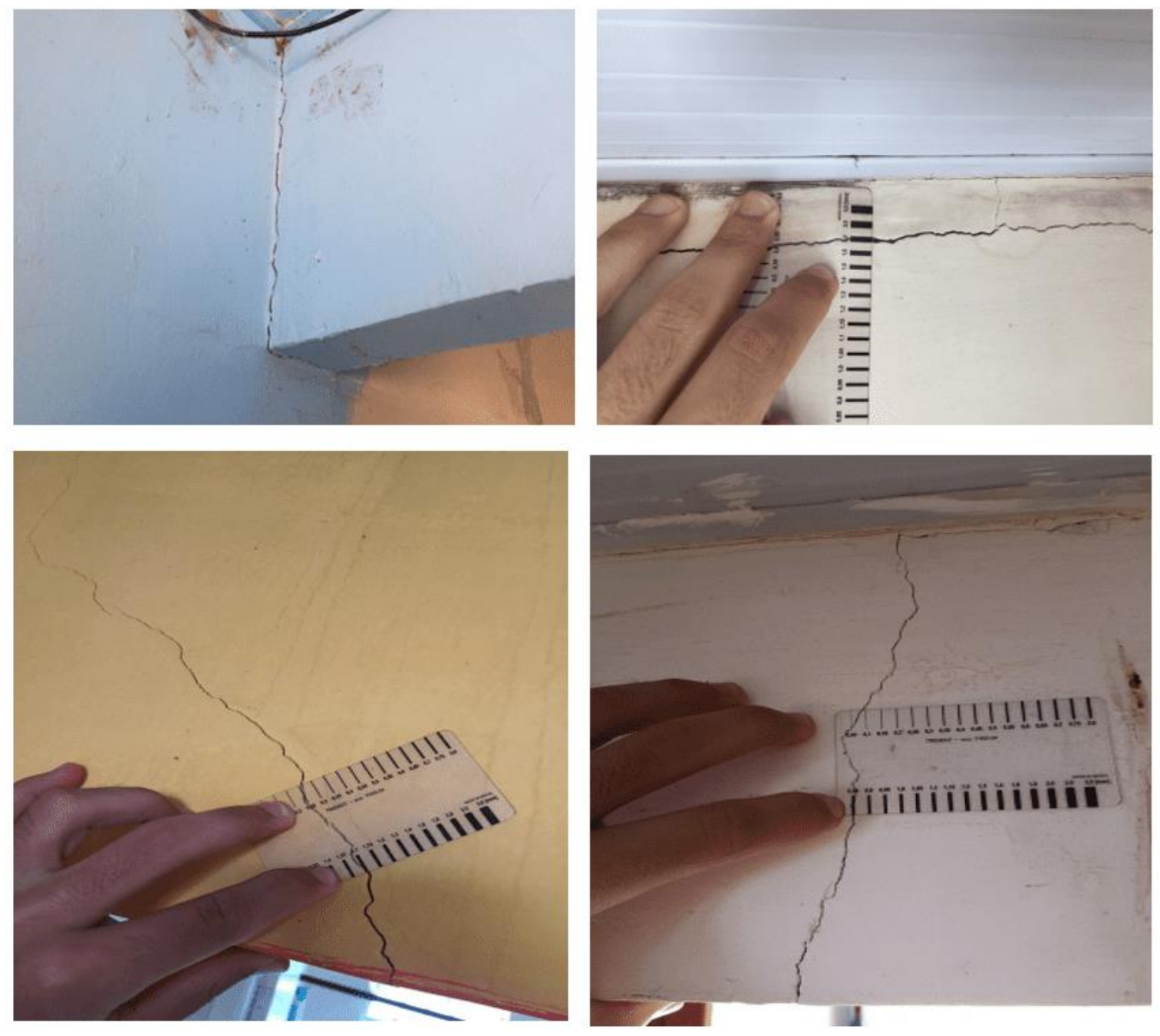

Fonte: Autores (2018).

Nas casas observadas, percebeu-se a ocorrência de fissuras em locais onde tem a presença de componentes do sistema elétrico, como quadros do sistema elétrico, caixas de passagem e eletrodutos, de acordo com as figuras 8 e 9 . 
Figura 8, 9 - Fissuras devido a componentes do sistema elétrico.
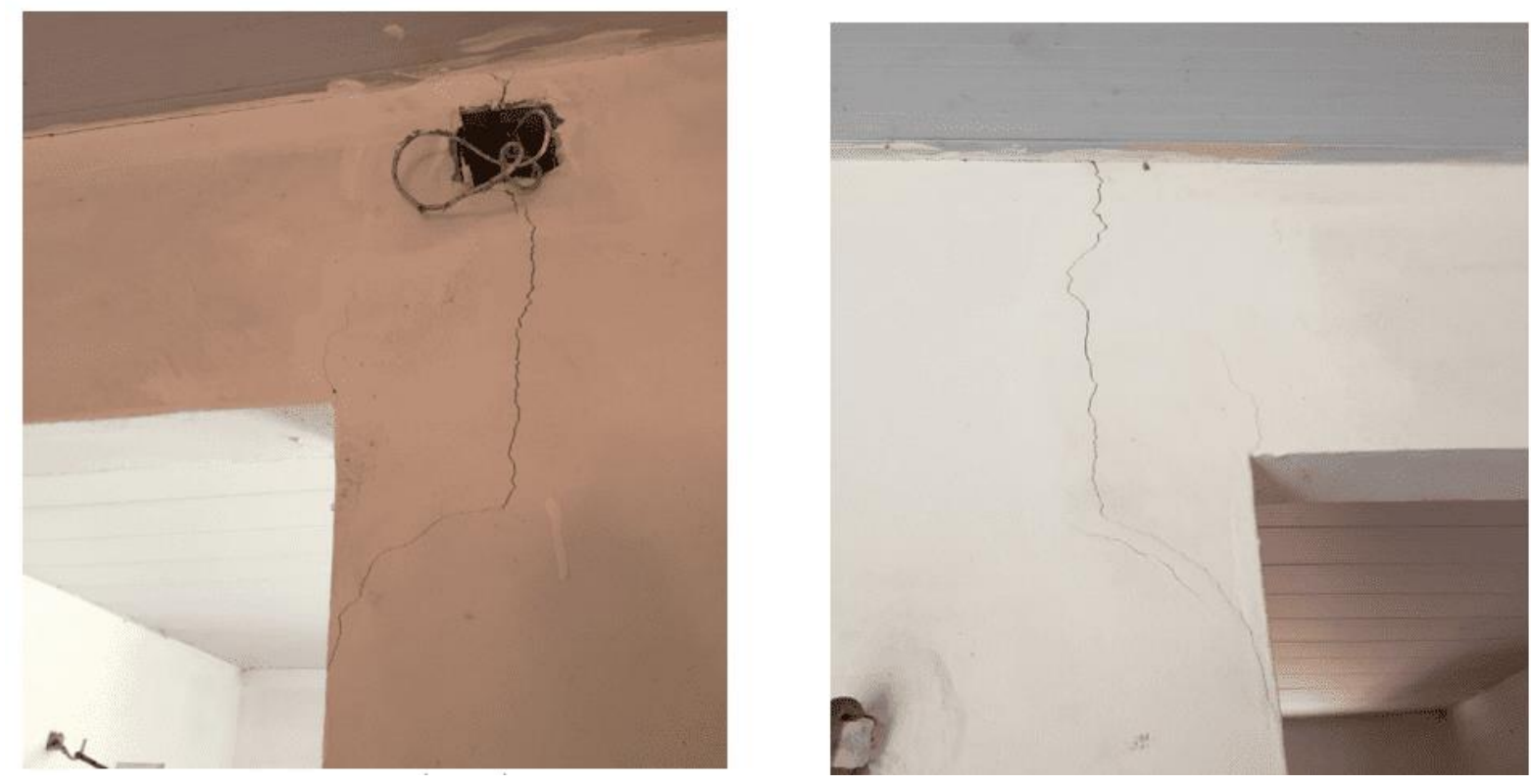

Fonte: Autores (2018).

$\mathrm{Na}$ infraestrutura, verificou-se que a fundação do tipo radier, não tem alvenaria de contenção, a lona plástica utilizada para impermeabilização do radier estava deteriorada e a armação do radier, a tela soldada estava exposta a agentes ambientais agressivos externos, do ambiente, como oxigênio (ar), umidade (água), ou internos, incorporados ao concreto e a heterogeneidade da estrutura, ocorrendo a despassivação do aço e resultando na corrosão da armadura, ocasionando fissuração no radier e desagregação do concreto, que garante o recobrimento da armadura. As imagens a seguir, observa-se as patologias no radier:

Figura 10, 11, 12 e 13 - Fundação das unidades habitacionais.
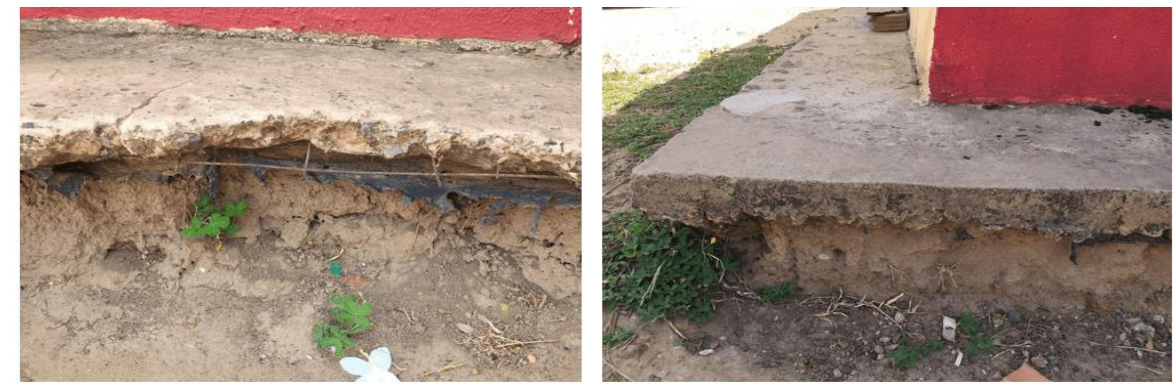

Fonte: Autores (2018).

RC: 49297

Disponível em: https://www.nucleodoconhecimento.com.br/engenharia-civil/fissuras-em-paredes 


\section{CONSIDERAÇÕES FINAIS}

O estudo apresenta os resultados obtidos de um levantamento sobre a ocorrência de patologias como fissuras e rachaduras nas estruturas de concreto das unidades habitacionais de um conjunto residencial, localizado em São José de Ribamar Maranhão.

O trabalho apontou diferentes manifestações patológicas, como fissuras, trincas e rachaduras nas unidades habitacionais do grupo amostral.

Nota-se que os resultados apresentados, a manifestação patológica mais comum foi à fissura (100\%), seguido das trincas $(70 \%)$ e rachaduras (10\%). Dessa forma, podese perceber que $70 \%$ das casas que inicialmente apresentaram fissuras, atualmente evoluíram para trincas, o que quer dizer que está havendo um grande acréscimo das fissuras com o passar do tempo, o que é confirmada na aplicação do questionário com os moradores, onde quando questionados, responderam que perceberam o aumento das fissuras com o tempo, e em $10 \%$ das casas, já é evidente a incidência de rachaduras, o que significa que essa situação demonstra a existência de riscos as estruturas de concreto e a integridade dos moradores.

Logo, devido aos problemas patológicos serem evolutivos e se agravarem com o tempo, além de acarretar outros problemas associados ao inicial, seriam adequados que fosse tomada medidas de proteção da estrutura, com a implantação de um programa de manutenção periódica, uma vez que o conjunto residencial em estudo, já apresenta uma periodicidade de cinco anos de utilização, evitando o agravamento das patologias encontradas.

Esse programa de manutenção deve levar em conta a importância da obra, a vida útil prevista, a agressividade das condições ambientais de exposição e a natureza dos materiais e medidas protetoras adotadas.

Essas manifestações patológicas têm consequências graves na durabilidade da estrutura, pois são veículos que permitem a entrada de agentes externos agressivos 
para o interior da estrutura, fazendo com que resulte na corrosão das armaduras e, consequentemente, na desagregação da capa de concreto do cobrimento da armadura.

Chama-se a atenção para a importância de se analisar todas as recomendações e especificações técnicas, durante a fase de concepção de projeto e fiscalização no decorrer da execução, uma vez que ocorrência de muitas patologias são associadas a procedimentos inadequados e a erros no processo executivo ou deficiência da completa execução do processo construtivo.

Por meio dos estudos realizados, pode-se afirmar que as maiorias dos problemas que apresentam nas estruturas da edificação, poderiam ser minimizadas ou evitadas, caso um controle de qualidade rigoroso durante o processo da construção tivesse ocorrido, aliado a manutenção preventiva e corretiva das estruturas de concreto.

Assim, acredita-se que este artigo possa contribuir para projetistas, construtores e usuários, em relação a cuidados com especificação de técnicas, como, por exemplo, a execução da estrutura, assim como sua utilização.

Para trabalhos futuros, sugere-se a investigação patológica em um maior grupo amostral de unidades habitacionais do conjunto residencial, enriquecendo este artigo e também um estudo mais detalhado da estrutura de concreto, assim como as causas e origens das manifestações patológicas, uma vez que o diagnóstico adequado e completo é aquele que esclarece todos os aspectos do problema, a saber: sintomas, mecanismos, origem, causas e consequências.

\section{REFERÊNCIAS}

ANDRADE, J.J.O. Durabilidade das estruturas de concreto armado: análise das manifestações patológicas nas estruturas no estado de Pernambuco. Dissertação (Mestrado), Universidade Federal do Rio Grande do Sul, Porto Alegre, 1997. 
ANDRADE, T.; SILVA, A.J.C. Patologia das Estruturas. In: ISAIA, Geraldo Cechella. (Ed) Concreto: In.: Concreto: Ensino, Pesquisa e Realizações. Editor: Geraldo Cechella Isaias. São Paulo: IBRACON, 2005.

ALMEIDA, R. MANIFESTAÇÕES PATOLÓGICAS EM PRÉDIO ESCOLAR: UMA ANÁliSE QUALITATIVA E QUANTITATIVA. Dissertação de Mestrado, PPGEC/UFSM, 2008.

ASSOCIAÇÃO BRASILEIRA DE NORMAS TÉCNICAS. ABNT NBR 6118: Projeto de estruturas de concreto. Rio de Janeiro, 2014.

ABNT NBR 16055: Parede de concreto moldada no local para a construção de edificações. Rio de Janeiro, 2012.

CARVALHO, R.C.; FIGUEIREGO FILHO, J.R. Cálculo e detalhamento de estruturas usuais de concreto armado: segundo a NBR 6118 e a proposta de 1999 (NB1/99). São Paulo, 2011.

CORSINI, Rodnei. Trinca ou fissura? Como se originam, quais os tipos, as causas e as técnicas mais recomendadas de recuperação de fissuras. 2010. Disponível em: <http://techne.pini.com.br/engenharia-civil/160/trinca-ou-fissura-comose-originam-quais-ostipos- 285488-1.aspx>. Acesso em outubro de 2018.

LOTTERMANN, Fabrício Nunes da. PATOLOGIAS EM ESTRUTURAS DE CONCRETO: ESTUDO DE CASO. Trabalho de Conclusão do Curso de Graduação em Engenharia Civil, Universidade Regional do Noroeste do Estado do Rio Grande do Sul, ljuí, 2013.

MISURELLI, H.; MASSUDA, C. Paredes de Concreto. Revista Téchne, n. 147, p. 7478, jun. 2009.

OLIVEIRA, Alexandre Magno de. FISSURAS, TRINCAS E RACHADURAS CAUSADAS POR RECALQUE DIFERENCIAL DE FUNDAÇÕES. Trabalho de final 
de curso de especialização em Gestão em Avaliações e Perícias da Universidade Federal de Minas Gerais, Belo Horizonte, 2012.

PONZONI, J. Paredes de concreto moldadas in loco: verificação do atendimento às recomendações da norma ABNT NBR 16055/2012 nos procedimentos executivos em obra de edifício residencial. Trabalho de Diplomação (Graduação em Engenharia Civil) - Escola de Engenharia, Universidade Federal do Rio Grande do Sul, Porto Alegre, 2013.

SOUZA, V. C.; RIPPER, T. Patologia, recuperação e reforço de estruturas de concreto. São Paulo: Pini, 1998.

Enviado: Dezembro, 2019.

Aprovado: Abril, 2020. 